\title{
Compression property of waste polyurethane rubber/unsaturated polyester composite cubes
}

\author{
S. Enoki ${ }^{1}$, T. Tsujitan ${ }^{2}$ \& J. Yamashita ${ }^{2}$ \\ ${ }^{1}$ Department of Mechanical Engineering, \\ Nara National College of Technology, Japan \\ ${ }^{2}$ Nara National College of Technology, Japan
}

\begin{abstract}
This paper describes a method to recycle waste polyurethane rubbers. Waste rubbers after manufacturing rubber products and most of the used rubber products have affected bad effects on the environment. In the case of larger rubber products, the waste rubbers and the used products have been recycled. However the waste rubbers of smaller rubber products and the used products are not recycled and are incinerated. An aseismatic mat is one of the smaller products and it is made of polyurethane rubber. The mats are manufactured a lot in Japan, so a lot of waste rubbers occur and are incinerated. In order to recycle the waste polyurethane rubbers, we created a composite cube as a structural material by using the waste rubbers. The composite cube had $15 \mathrm{~mm}$ on a side. Unsaturated polyester was used as a matrix, and then the waste polyurethane rubbers were put in the unsaturated polyester. The waste polyurethane rubbers were minced and the minced rubbers were made into a ball. Some composite cubes on different quantities of the rubbers were prepared. Static compression tests were carried out with the composite cubes and with a cube made of only unsaturated polyester. Comparing with the load-displacement curves, it has been shown that a maximum load of the $0.1 \mathrm{~g}$-rubber-containing composite cube is larger than that of the rubber-free cube. However it has been shown that a maximum load of the $0.5 \mathrm{~g}$-rubber-containing composite cube is not larger than that of the rubber-free cube. So it is possible that polyurethane rubber reinforce unsaturated polyester, if the rubber is minced and is made into a ball and is used in the appropriate contained amount.
\end{abstract}

Keywords: waste rubber, recycle, composite, compression property. 


\section{Introduction}

Waste rubbers after manufacturing rubber products and most of the used rubber products have affected bad effects on the environment. In the case of larger rubber products which are usually manufactured in big companies, the waste rubbers and the used rubber products have been recycled $[1,2]$. For example, waste tire rubbers are used for a pavement material. In the case of smaller rubber products which are usually manufactured in small companies, the wastes and the used smaller products are not recycled and are incinerated.

An aseismatic mat is one of the smaller products and it is made of polyurethane rubber. The mat was developed for keeping up home electric appliances and furniture in quake-prone Japan. A lot of aseismatic mats are manufactured in Japan, so a lot of waste polyurethane rubbers occur and are incinerated. It is difficult to recycle them, because the polyurethane rubber is thermosetting and is not able to re-thermoform. Additionally, all of the waste rubbers are too small and different in shape and in size to be recycled.

In order to recycle the waste polyurethane rubbers, we created a composite cube as a structural material by using the waste rubbers. Unsaturated polyester was used as a matrix, and then the waste polyurethane rubbers were put in the unsaturated polyester. If compression properties of the polyurethane rubber/unsaturated polyester composite cubes were better than that of a rubberfree cube, the composite cubes will be able to recycle the waste polyurethane rubbers.

In this study, therefore, compression tests were carried out to examine the compression properties of the composite cubes and the rubber-free cube.

\section{Composite cubes}

The composite cube had $15 \mathrm{~mm}$ on a side and unsaturated polyester was used as a matrix, and then the waste polyurethane rubbers were put in the unsaturated polyester. In this section, characteristics of the polyurethane rubber and how to put the waste rubbers in the matrix were described. Then a procedure for preparing the composite cubes was proposed.

\subsection{Waste polyurethane rubbers}

Aseismatic mats are manufactured in Japan and a lot of waste polyurethane rubbers occur as shown in Figure 1(a). The polyurethane rubber is thermosetting and is not able to re-thermoform. And all of the waste rubbers are different in shape and in size as shown in Figure 1(b). To solve the problems, we focused on characteristics of the polyurethane rubber. The characteristics are rubber elasticity and high-adhesive property. After the waste polyurethane rubbers were minced, the minced rubber can be made into a ball because of the high-adhesive property. It was thought that behaviour of the balled-up rubber was as same as the rubber elasticity of a solid polyurethane rubber when they were put in the unsaturated polyester. 


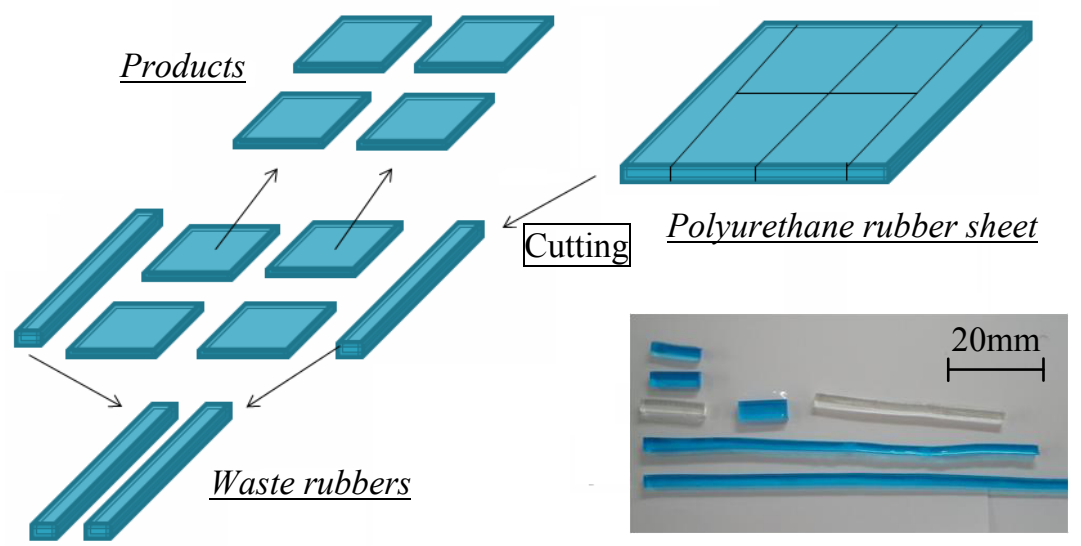

(a) Production flow of aseismatic mats.

(b) Waste polyurethane rubbers. (different in size and in shape)

Figure 1: Generating waste polyurethane rubbers and photo of the wastes.

A $0.1 \mathrm{~g}$ balled-up rubber, a $0.3 \mathrm{~g}$ balled-up rubber and a $0.5 \mathrm{~g}$ balled-up rubber were prepared as shown in Figure 2 because of the minced rubbers was able to be adjusted. The different quantities of balled-up rubbers were put in unsaturated polyester and composite cubes contained different quantities of rubber were prepared.

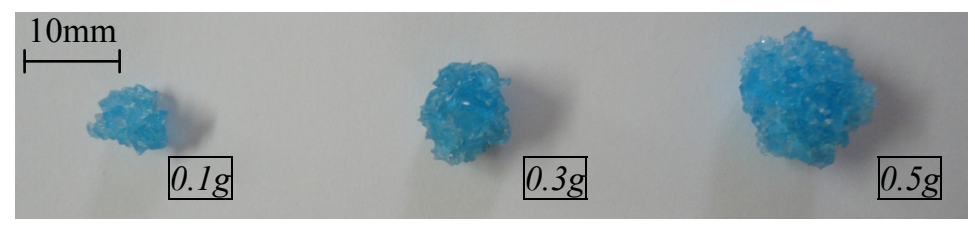

Figure 2: $\quad$ Photo of balled-up minced waste polyurethane rubbers.

\subsection{Preparing composite cubes}

Prepared cubes are shown in Table 1. A mold was used for preparing the cubes which size was $15 \mathrm{~mm}$ on a side. Unsaturated polyester mixed with a hardener was casted into the mold. When rubber-containing composite cubes were prepared, the balled-up minced waste polyurethane rubbers shown in Section 2.1 were put in the unsaturated polyester in the middle of the casting. All of the balled-up rubbers put in the centre of the each cube as shown in Figure 3.

For comparison, rubber-free cubes which were made of only unsaturated polyester were prepared. Moreover, the other rubber-containing composite cubes, using balled-up rubbers that debased adhesive, were prepared. The lowadhesive rubbers were made by leaving balled-up rubbers in the atmosphere for about 2 months. It is predicted that the high-adhesive rubber/unsaturated 
Table 1: $\quad$ Prepared rubber-containing composite cubes and rubber-free cube.

\begin{tabular}{|c|c|c|c|}
\hline & $\begin{array}{l}\text { Waste Polyu } \\
\text { Quantities }\end{array}$ & $\begin{array}{l}\text { ane Rubber } \\
\text { Adhesive }\end{array}$ & Matrix \\
\hline Rubber-free Cube & - & - & \multirow{7}{*}{ Unsaturated Polyester } \\
\hline \multirow{6}{*}{$\begin{array}{c}\text { Composite Cubes } \\
\text { contained } \\
\text { balled-up rubber }\end{array}$} & Minced $0.1 \mathrm{~g}$ & \multirow{3}{*}{ High } & \\
\hline & Minced $0.3 \mathrm{~g}$ & & \\
\hline & Minced $0.5 \mathrm{~g}$ & & \\
\hline & Minced $0.1 \mathrm{~g}$ & \multirow{3}{*}{ Low } & \\
\hline & Minced $0.3 \mathrm{~g}$ & & \\
\hline & Minced $0.5 \mathrm{~g}$ & & \\
\hline
\end{tabular}

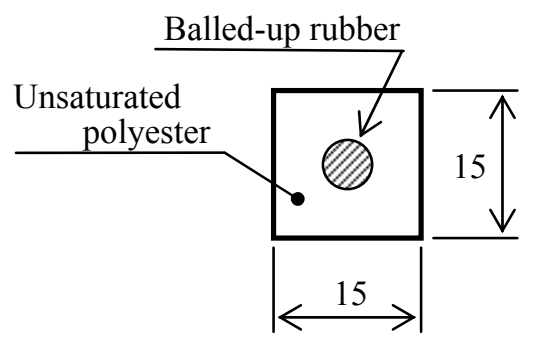

(a) A section of composite cube.

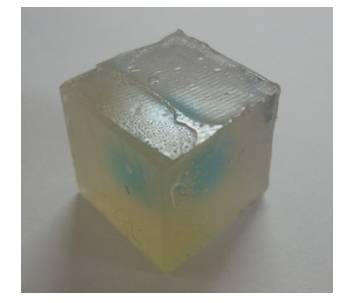

(b) A composite cube.

Figure 3: Schematic view and photo of polyurethane rubber/unsaturated polyester composite cube.

polyester composite cubes have higher compression properties than the lowadhesive rubber/unsaturated polyester composite cubes.

\section{Compression test}

Static compression tests were carried out with the cubes shown in Section 2. Hydraulic type universal testing machine (SHIMADZU CORPORATION Model: UH-500kNI) was used for the static compression tests. The test speed is set on $2 \mathrm{~mm} / \mathrm{min}$. and the stroke is set on $2 \mathrm{~mm}$. Mechanical model of the compression test and a photo of the testing situation are shown in Figure 4. Lubricant agent was applied on upper and lower planes of the cubes. It reduces friction on the planes faced on upper testing head and testing platform. 


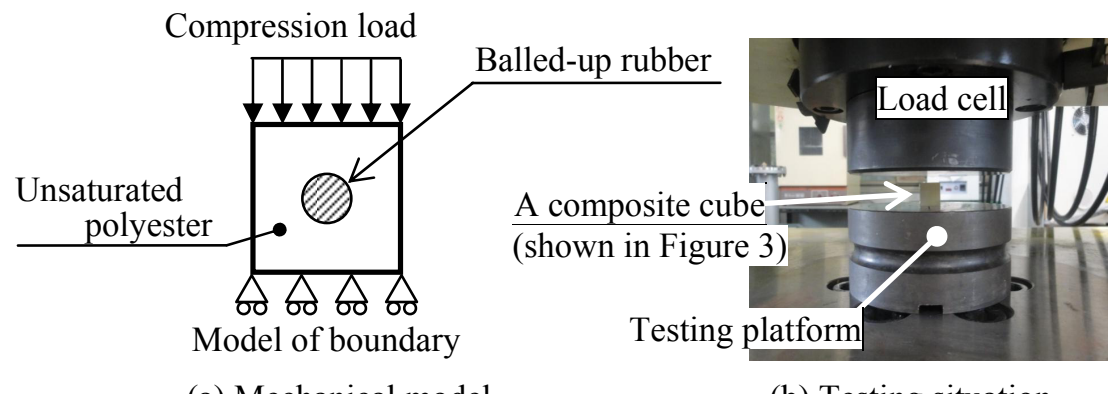

(a) Mechanical model

(b) Testing situation.

Figure 4: Mechanical model of balled-up rubber/unsaturated polyester composite cube and a photo of compression test for the cube.

\section{Results and discussion}

Compression property was evaluated with load-displacement curves and maximum compression stress values.

\subsection{Load-displacement curve}

Comparing with load-displacement curves shown in Figure 5, a maximum load of the composite cube contained $0.1 \mathrm{~g}$ balled-up rubber is larger than that of the rubber-free cube. However it is shown that maximum loads of the composite cubes contained $0.3 \mathrm{~g}$ and $0.5 \mathrm{~g}$ balled-up rubbers are not larger than that of the rubber-free cube. Moreover the maximum loads of the composite cubes decrease with increasing contained amount of the rubbers.

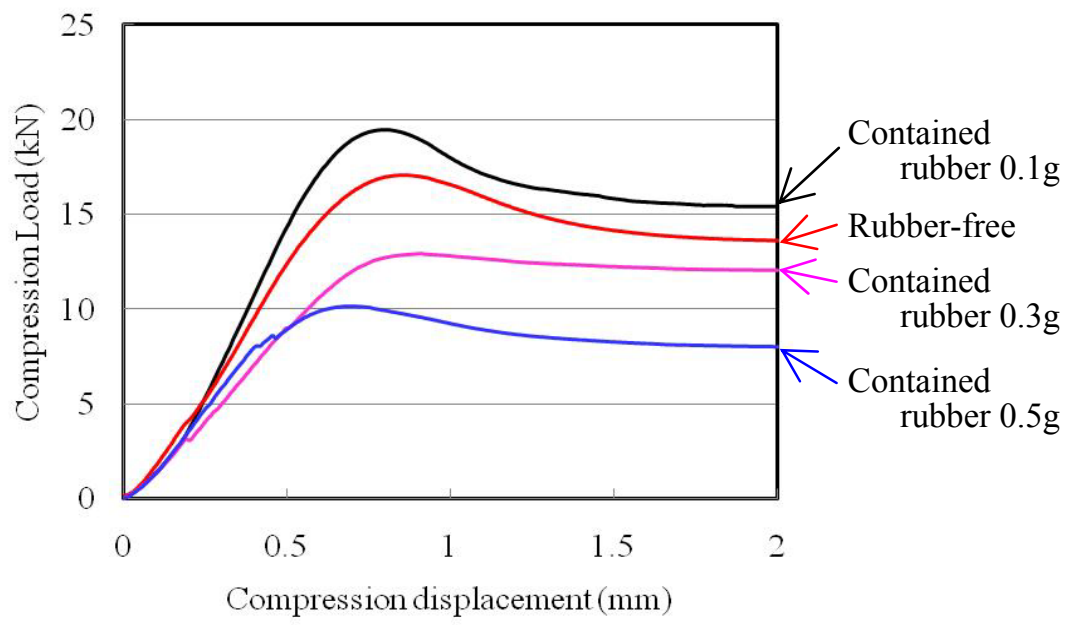

Figure 5: Comparing with load-displacement curves of cubes with different contained amount of rubbers. 


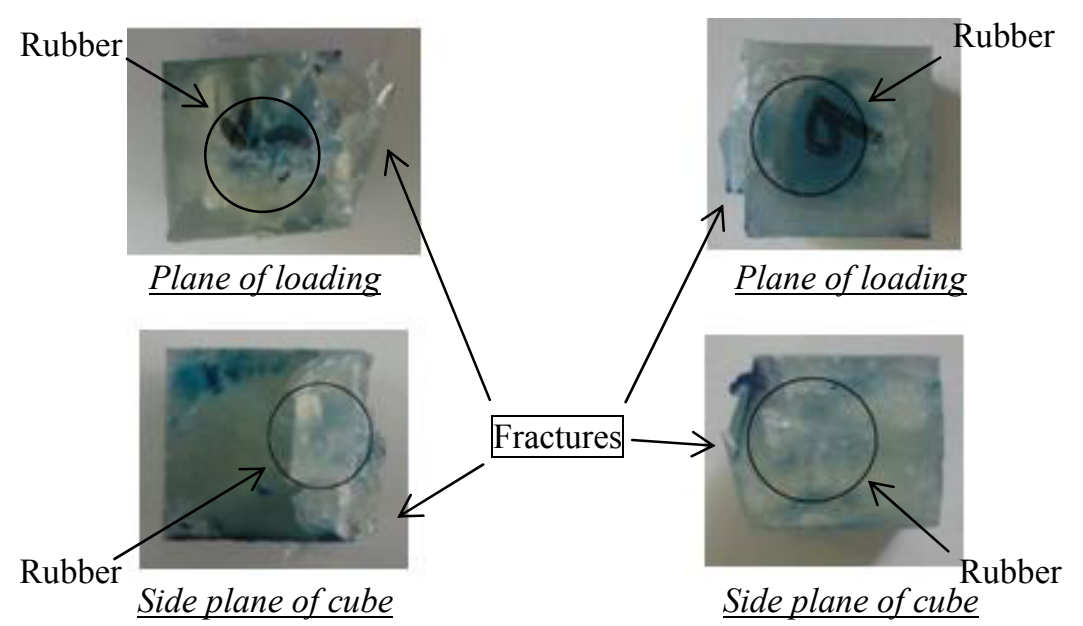

(a) Contained $0.3 \mathrm{~g}$ balled-up rubber.

(b) Contained $0.5 \mathrm{~g}$ balled-up rubbers.

Figure 6: $\quad$ Typical of fracture morphology after compression tests.

Composite cubes contained $0.3 \mathrm{~g}$ and $0.5 \mathrm{~g}$ balled-up rubbers after compression tests are shown in Figure 6. The side planes were broken in both composite cubes. This fracture morphology is thought to be typical.

An anticipate fracture mechanism of balled-up polyurethane rubber/unsaturated polyester composite cubes is thought as shown in Figure 7. The balled-up rubbers are thought to deform widely to side planes of the cubes and spread the unsaturated polyester from inside after compressive loading. It is because the rubber Poisson ratio 0.45 is larger than the unsaturated polyester Poisson ratio 0.34 . The situation is similar to occurring hydrostatic pressure. Therefore it is thought that the composite cube can support higher loading, comparing with a rubber-free cube. This case agrees with the 0.1 g-rubbercontaining composite cubes. However, in the case that quantities of the contained rubber are a lot, thickness of a side plane of the cubes is small. Therefore it is easy to be occurred plastic deformation and to be broken at the side plane. This case agrees with the composite cubes contained $0.3 \mathrm{~g}$ and $0.5 \mathrm{~g}$ balled-up rubbers.

\subsection{Maximum compression stress}

The anticipate fracture mechanism, shown in Figure 7, is thought to be based on high-adhesive property of the polyurethane rubber. The minced rubbers can be made into a ball by using the high-adhesive property. To consider the influence of adhesive property on the compression property of the composite cubes, therefore, maximum compression stress values were calculated. Nominal stress was used in this study. Figure 8 shows the maximum compression stress values compared rubber-free cubes with composite cubes contained high-adhesive minced rubbers and low-adhesive ones. 

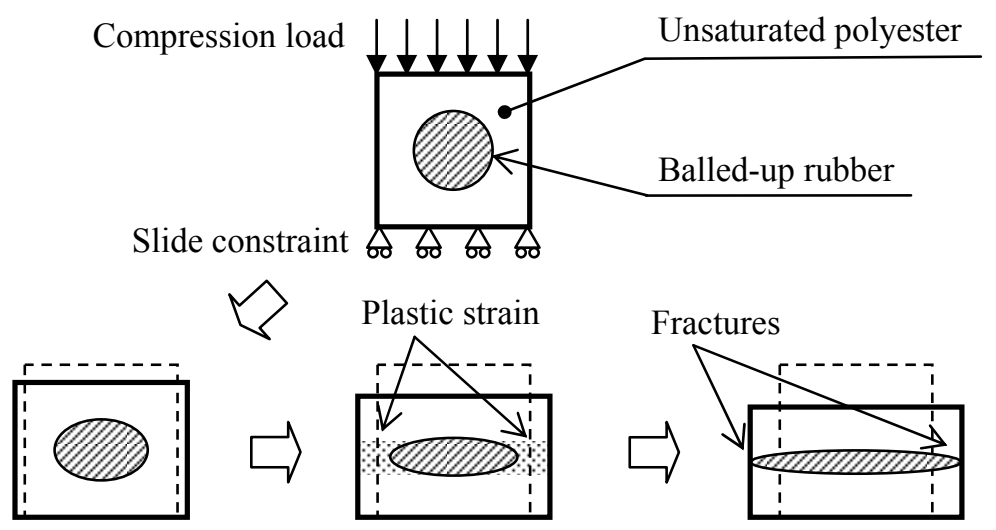

Figure 7: Anticipated fracture mechanism of balled-up rubber/unsaturated polyester composite cube.

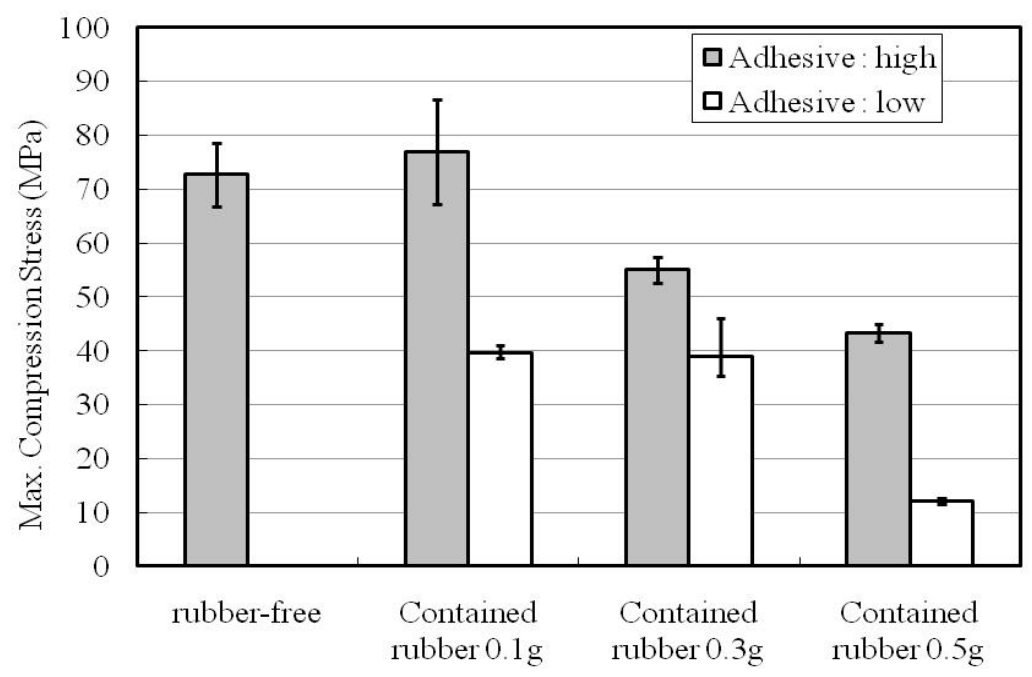

Figure 8: Comparing with maximum compression stresses of cubes having different quantities of contained rubbers and different adhesive properties of contained rubbers.

In the case of containing the high-adhesive minced rubbers, maximum compression stress values show a same trend of the maximum loads shown in Section 4.1. However, maximum compression stress values of the composite cubes contained low-adhesive minced rubbers are smaller than that of the composite cubes contained high-adhesive ones independently of contained quantities.

The balled-up minced polyurethane rubber is similar to an aggregate of fine polyurethane rubber fragments as shown in Figure 9. In the case of high- 
adhesive rubber, there are few voids in the aggregate and the aggregate has rubber elasticity in the unsaturated polyester. In the case of low-adhesive rubber, there are a lot of voids in the aggregate and it is thought that the balled-up rubber dose not has rubber elasticity.
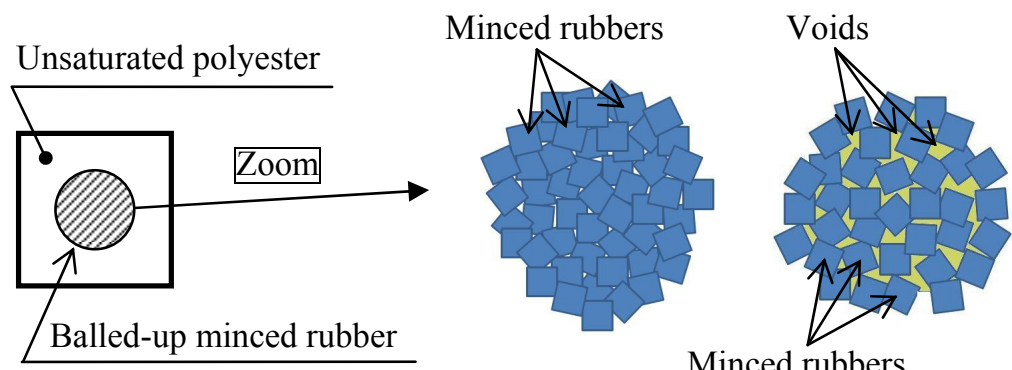

Minced rubbers
(a) Contained
high-adhesive rubbers.
(b) Contained low-adhesive rubbers.

Figure 9: $\quad$ Model of minced rubber in unsaturated polyester.

\section{Conclusion}

It is possible that polyurethane rubber reinforce unsaturated polyester if the rubber is minced and is made into a ball and is used in the appropriate quantity. The quantity is $0.1 \mathrm{~g}$ in the case of composite cubes which size is $15 \mathrm{~mm}$ on a side. It is thought that waste polyurethane rubbers can recycle as a structural material.

\section{Acknowledgements}

We thank SHINAGAWA Co., Ltd. (Rubber Manufacturing) and RODAN21 Co., Ltd. (Manufacturing Coordination) for the provision of waste polyurethane rubbers.

\section{References}

[1] Masahito FUJII, Kenji HIMENO, Kenichi KOUGO \& Masato MURAYAMA, Physical Properties of Asphalt Rubber Mixtures, $6^{\text {th }}$ ICPT, Sapporo, Japan, July, 2008.

[2] Kenzo FUKUMORI \& Mitsumasa MATSUSHITA, Material Recycling Technology of Crosslinked Rubber Waste, R\&D Review of Toyota CRDL Vol. 38 No.1, p.39-47, 2003. 